\title{
Women's Satisfaction with and Reasons to Seek Bariatric Surgery-a Prospective Study in Sweden with 1-Year Follow-up
}

\author{
Mari Hult ${ }^{1,2}$ (D) Stephanie E. Bonn ${ }^{1} \cdot$ Lena Brandt $^{1} \cdot$ Mikael Wirén $^{3} \cdot$ Ylva Trolle Lagerros ${ }^{1,4}$
}

Published online: 6 April 2019

(C) The Author(s) 2019

\begin{abstract}
Background/Objectives Despite profound weight loss after bariatric surgery, some patients are dissatisfied with the results. Presurgery expectations, as well as post-surgery items of satisfaction, need to be clarified. The main objective in this study was to investigate the primary reasons to seek bariatric surgery and assess items of satisfaction 1-year post-surgery.

Subjects/Methods This is a prospective cohort study of women $(n=50)$ undergoing bariatric surgery in Stockholm, Sweden. Presurgery assessment included reasons to seek surgery, expected weight loss, co-morbidities, and quality of life. Post-surgery assessment included items of satisfaction, weight loss, co-morbidities, and quality of life. In total, two women did not undergo surgery, and 40 women had complete data from all pre- and post-surgery assessments.

Results Mean change in body mass index (BMI) pre- and post-surgery was $-12.9(3.7) \mathrm{kg} / \mathrm{m}^{2}$. At 1-year post-surgery, the mean percent of excess weight loss (\%EWL) was 86.9 (26.3). Pre-surgery, the most reported reason to seek surgery was "weight loss" $(47.9 \%)$, while the most reported item of satisfaction post-surgery was "improved self-esteem" (55.6\%). Satisfaction with the result 1-year post-surgery was associated with the extent of \%EWL. Satisfied patients $(n=32)$ had a mean \%EWL of 94.6 (22.9), while those not satisfied $(n=8)$ had a mean \%EWL of $59.9(17.6)$.

Conclusions The primary reason to seek bariatric surgery was weight loss. However, despite profound weight loss, improved self-esteem was the item of most satisfaction post-surgery. Our findings may be useful in the clinical setting when informing patients pre-surgery about what to expect as well as when meeting a patient post-surgery to discuss results.
\end{abstract}

Keywords Bariatric surgery $\cdot$ Patient expectations $\cdot$ Patient satisfaction $\cdot$ Weight loss $\cdot$ Health-related quality of life $\cdot$ Co-morbidity

\section{Introduction/Purpose}

Bariatric surgery is established as a safe and successful treatment for morbid obesity [1-3]. However, despite the good results with regard to weight loss after surgery, patients are not always satisfied due to unrealistic expectations [4-6]. Patients undergoing non-surgical weight loss treatments have similar unrealistic expectations but some studies indicate that high expectations result in higher level of weight loss [7-10]. Previous studies exploring patients' expectations of bariatric
Mari Hult

mari.hult@ki.se

Stephanie E. Bonn

stephanie.bonn@ki.se

Lena Brandt

lena.brandt@ki.se

Mikael Wirén

mwiren68@gmail.com

Ylva Trolle Lagerros

ylva.trolle@ki.se
1 Department of Medicine, Solna, Karolinska Institutet, Clinical Epidemiology Unit T2, Karolinska University Hospital, 171 76 Stockholm, Sweden

2 Department for Upper GI Cancer, Karolinska University Hospital, Huddinge, Sweden

3 Department of Clinical and Experimental Medicine, Division of Surgery, Orthopedics and Oncology, Linköping University, Linköping, Sweden

4 Obesity Center, Academic Specialist Center, Stockholm Health Service, Stockholm, Sweden 
surgery have primarily focused on weight loss, and in some extent quality of life. Few have investigated the impact of other expectations of surgery, and whether these are met [11]. To date, no association between patients' expectations and postoperative outcomes has been shown $[12,13]$. Unrealistic expectations do not seem to be associated with postoperative weight loss $[14,15]$. Preoperative reasons to seek bariatric surgery have been explored to some extent [16-18], but have not been prospectively followed up after surgery.

This study aims to explore the main reasons for seeking obesity surgery and to further study which items the patients report to be most satisfied with post-surgery in a Swedish female population. Furthermore, we aimed to study patients' perceived satisfaction with the surgical outcome and its association to post-surgery weight loss and quality of life. Our hypotheses are that independently of patient-related factors, weight loss remains the most important reason to seek surgery, and the degree of satisfaction with the post-surgery result depends on the amount of weight loss.

\section{Materials and Methods}

Between January 2012 and January 2013, 52 women with obesity accepted for laparoscopic Roux-en-Y gastric bypass (LRYGB) procedures at Ersta Hospital situated in Stockholm, Sweden, were invited to participate in the study. The inclusion criterion was to qualify for bariatric surgery in Sweden according to the national guidelines (having a BMI $>40 \mathrm{~kg} / \mathrm{m}^{2}$, or a BMI > $35 \mathrm{~kg} / \mathrm{m}^{2}$ and a co-morbidity, e.g., diabetes). Exclusion criteria were previous bariatric surgery, age less than 18 years, and inability to read or understand Swedish. The Regional Ethical Review Board in Stockholm approved the study (Dnr: 2012/302-31/1). Informed consent was obtained from all participants prior to study start.

The participants were asked to respond to two questionnaires (see Appendix 1 and 2). The first questionnaire was handed out at the surgical outpatient clinic at inclusion within 4 weeks prior to surgery to assess baseline variables. The second questionnaire was sent to the participant with the invitation to 1-year follow-up at the surgical outpatient clinic. Both questionnaires assessed comorbidities, medication use, marital status, children, occupation, and education. Medication for hypertension, dyslipidemia, diabetes, depression, and treatment for sleep apnea were assessed and answers were cross-checked with medical records. In the first questionnaire, participants were asked to report their primary reasons for seeking surgery. Post-surgery, participants were asked the question "Are you satisfied with your weight loss after surgery?" and responded "yes" or "no" to that. They were also asked to rate what items corresponding to the reasons to seek surgery they were most satisfied with post-surgery.
Although not the same constructs, when reporting reasons to seek surgery at baseline and items of satisfaction post-surgery, participants were asked to rank the same 14 items according to a Likert scale ranging from 1 (not important) to 5 (very important). These items were the result of pre-study interviews with both patients with obesity and physicians working with this patient group. The items were weight loss, taking less medication, improvement in comorbidities, having less pain, chances of being employed, improvements in social life, expectations to live longer, improved intimacy, improved selfesteem, improved fertility, improved ability to perform sports, having smaller cloth size, improved psychiatric health, and improved work performance. Participants were also given the possibility to add free text. Finally, they were asked to rank their top three reasons for seeking surgery or top three items of satisfaction.

A validated quality-of-life questionnaire, the SF-36, was used to assess general quality of life at baseline and post-surgery [19-26]. It comprises eight domains: physical function (PF), role limitations due to physical problem (RP), bodily pain (BP), general health (GH), vitality (VT), social function (SF), role limitations due to an emotional problem (RE), and mental health (MH). The domains can be summarized into two summary scales: the physical component summary scale (PCS) and the mental component summary scale (MCS). The PCS is based on PF, RP, BP, and GH; and the MCS is based on VT, SF, RE, and MH. The summary scales are calculated and standardized according to a norm-based scoring between 0 (poor health) and 100 (good health) with a mean of 50 and a standard deviation of 10 .

In total, 50 women, completed the baseline questionnaire. Of these, two women did not undergo surgery and eight did not complete the post-surgery questionnaire. To assess potential reasons for not completing the study, we examined the medical records of the non-responders; psychiatric comorbidity $(n=4)$, reoperation $(n=1)$, other surgical procedures $(n=1)$, emigration $(n=1)$, and cancer diagnosis prior to the planned gastric bypass procedure leading to the procedure being canceled $(n=1)$ were found. From the medical records, we were able to obtain information on body weight 1 year post-surgery for six of the eight participants who did not complete the study. Pre-surgery, BMI were calculated using measured weight and height collected at the outpatient clinic when the participants were accepted for surgery. Post-surgery BMI were calculated from weight either collected at the 1-year follow-up at the outpatient clinic or self-reported weight. Change in BMI was calculated by subtracting BMI post-surgery from BMI pre-surgery. In calculations of excess percent weight loss $(\% \mathrm{EWL})$, the ideal weight was defined as $\mathrm{BMI}=25 \mathrm{~kg} / \mathrm{m}^{2}$. 


\section{Statistical Analysis}

Characteristics of study participants are presented as numbers $(n)$ and percentages (\%) as well as mean values and standard deviations (SD). Differences in changes in BMI, \%EWL, and SF36 scores between participants who were classified as satisfied vs. not satisfied were tested for using the WilcoxonMann-Whitney $U$ test. All analyses were performed using SAS version 9.4.

\section{Results}

Characteristics of the study population are shown in Table 1. In total, 40 out of 50 women that completed the pre-surgery questionnaire had complete data from all pre- and postsurgery assessments. The mean age at baseline, pre-surgery, was 37.5 (10.4) years. The mean pre-surgery BMI was 40.9 (5.2) $\mathrm{kg} / \mathrm{m}^{2}$ and the mean BMI 1-year post-surgery was 27.8 (5.3) $\mathrm{kg} / \mathrm{m}^{2}$. The mean change in BMI pre- and post-surgery was $-12.9(3.7) \mathrm{kg} / \mathrm{m}^{2}$. The mean percent excess weight loss (\%EWL) was 86.9 (26.3). The major comorbidities reported pre-surgery were arthrosis and/or musculoskeletal pain (52\%), and psychiatric disorders $(40 \%)$. These were reduced at the 1year post-surgery follow-up to 18 and $22 \%$, respectively. The reported use of antihypertensive medication was reduced from $16 \%$ pre-surgery to $6 \%$ post-surgery, use of lipid lowering medication decreased from 8 to $0 \%$ and reported consumption of analgesics went from 28 to $11 \%$. The only participant with insulin-treated diabetes pre-surgery was still on insulin treatment post-surgery.

The top three most important reasons for seeking surgery were slightly different from the top three items that the women reported to be most satisfied with post-surgery. The most common top three reasons pre-surgery were as follows: 1 . weight loss (47.9\%), 2. improved comorbidity (41.7\%), and 3. to live longer (35.4\%). The top three items of satisfaction postsurgery were as follows: 1 . improved self-esteem $(55.6 \%), 2$. weight loss (41.7\%), and 3. to live longer (38.9\%) (see Fig. 1). Additional other reasons for seeking surgery reported by participants pre-surgery in open text answer were "not to be a lazy mother," "public transports," "amusement parks," "better physical ability," and "less candida infections in skinfolds." Post-surgery only two items were added as items of satisfaction: "quality of life" and "respect from others."

Satisfaction with the weight loss result 1-year post-surgery was associated with the extent of \%EWL, Table 2. In total, 32 patients reported to be satisfied and 8 patients reported that they were not satisfied. The mean change in BMI was -13.4 (3.6) $\mathrm{kg} / \mathrm{m}^{2}$ among satisfied patients, and $-11.0(4.1) \mathrm{kg} / \mathrm{m}^{2}$ among unsatisfied participants $(p=0.06)$. Patients, who reported to be satisfied, had a mean \%EWL of 94.6 (22.9), while patients who reported that they were not satisfied, had a mean
$\%$ EWL of $59.9(17.6)(p=0.002)$. None of the satisfied patients had an \%EWL lower than $80 \%$. Age was not associated with the satisfaction $(p=0.54)$.

The mean mental component summary scale at baseline $(n=50)$ was 42.6 compared with 49.4 in the general Swedish female population [27], while it had increased to 45.8 postsurgery $(n=37)$. Improvements in the MCS were seen among 32 participants (86.5\%) 1-year post-surgery and 35 participants $(94.6 \%)$ scored higher in general health. The scoring of physical functioning was improved in 35 participants $(94.6 \%)$ and $34(91.9 \%)$ also improved in bodily pain 1-year post-surgery, Fig. 2. There was no significant association between patients' satisfaction after 1 year and the MCS or the PCS (Table 2).

\section{Discussion}

In this prospective study of 40 women undergoing bariatric surgery, weight loss was one of the top three reasons to seek bariatric surgery. Weight loss also remained one of the top items that the women were most satisfied with post-surgery, together with improved self-esteem and a desire for a longer life.

As expected, and in line with previous studies, weight loss was the most important reason to seek surgery [4]. Health issues and a wish for a longer life, the second and third most reported reasons for bariatric surgery in our study, have also been shown to be important in previous studies $[4,12,14,16$, $28,29]$. In a review of potential predictors for post-surgery success by van Hout et al. [29], the authors concluded that comorbidity was a strong motivator for seeking surgery. Wee et al. [4] found that health issues was the primary reason for seeking surgery among $84 \%$ of their patients $(n=44)$ in their pre-surgical survey. This was also confirmed in a second, larger study including 654 participants $(75.1 \%$ women) by the same author [28]. Thus, our results of primary reasons to seek bariatric surgery are in line with previous studies.

Post-surgery, improved self-esteem was ranked the most important factor for satisfaction, which has been shown in other studies as well $[14,30]$. Improved self-esteem is likely to be a reflection of a successful weight loss, as well as greater satisfaction with the result of the surgical procedure. Nonetheless, Dymek et al. [31] showed a significant increase in self-esteem within a few weeks post-surgery, which could suggest another mechanism than weight loss. In the article by Wolfe et al. [14], respondents reported that the weight loss significantly improved their community and professional relationships, another aspect that may increase self-esteem as well.

Comorbidity has previously been shown to be an important issue in this group of patients, but did not remain as one of the top three most important items of satisfaction post-surgery. This may be explained by the fact that our group of women generally were healthier than most populations with obesity. For example, only one out of 50 the women with obesity in our study had 
Table 1 Characteristics of the study population of Swedish women

\begin{tabular}{|c|c|c|}
\hline Characteristics & $\begin{array}{l}\text { Baseline }(n=50) \\
\text { No. }(\%)\end{array}$ & $\begin{array}{l}1 \text {-year post-surgery }(n=40) * \\
\text { No. }(\%)\end{array}$ \\
\hline \multicolumn{3}{|l|}{ Age (year) } \\
\hline$\leq 39$ & $28(56.0)$ & $20(50.0)$ \\
\hline$\geq 40$ & $22(44.0)$ & $20(50.0)$ \\
\hline \multicolumn{3}{|l|}{ Relations } \\
\hline Single & $19(38.0)$ & $18(45.0)$ \\
\hline Married/cohabiting & $31(62.0)$ & $22(55.0)$ \\
\hline \multicolumn{3}{|l|}{ Children } \\
\hline Yes & $35(70.0)$ & $26(65.0)$ \\
\hline No & $12(24.0)$ & $11(27.5)$ \\
\hline Missing & $3(6.0)$ & $3(7.5)$ \\
\hline \multicolumn{3}{|l|}{ Smoking } \\
\hline Yes & $7(14.0)$ & $6(15.0)$ \\
\hline No & $42(84.0)$ & $34(85.0)$ \\
\hline Missing & $1(2.0)$ & $0(0.0)$ \\
\hline \multicolumn{3}{|l|}{ Occupation } \\
\hline Working & $34(68.0)$ & $26(65.0)$ \\
\hline Study & $3(6.0)$ & $3(7.5)$ \\
\hline On sick-leave & $2(4.0)$ & $6(15.0)$ \\
\hline Unemployed & $11(22.0)$ & $5(12.5)$ \\
\hline \multicolumn{3}{|l|}{ BMI $\left(\mathrm{kg} / \mathrm{m}^{2}\right)^{*}$} \\
\hline$<30$ & $0(0.0)$ & $34(73.9)$ \\
\hline $30-40$ & $27(54.0)$ & $10(21.7)$ \\
\hline $40-45$ & $14(28.0)$ & $2(4.4)$ \\
\hline$>45$ & $9(18.0)$ & $0(0.0)$ \\
\hline \multicolumn{3}{|l|}{ Medication/treatment ${ }^{*}$} \\
\hline Diabetes medication & $1(2.0)$ & $1(2.0)$ \\
\hline Antihypertensive medication & $8(16.0)$ & $3(6.0)$ \\
\hline Lipid lowering medication & $4(8.0)$ & $0(0.0)$ \\
\hline CPAP for sleep apnea & $0(0.0)$ & $0(0.0)$ \\
\hline Anti-depressive medication & $20(40.0)$ & $12(24.0)$ \\
\hline Pain medication & $14(28.0)$ & $5(11.0)$ \\
\hline \multicolumn{3}{|l|}{ Other diagnosis $^{*}$} \\
\hline Psychiatric other than depression & $20(40.0)$ & $11(22.0)$ \\
\hline Arthrosis or other musculoskeletal disorder & $26(52.0)$ & $9(18.0)$ \\
\hline Infertility & $7(14.0)$ & $2(4.7)$ \\
\hline
\end{tabular}

BMI, body mass index; CPAP, continuous positive airways pressure

* Post-surgery data from $n=46$, additional data for $n=6$ collected from medical records including weight, medication, and diagnosis

diabetes, while other studies report up to $40 \%$ of diabetics in their study populations [14, 22, 23, 26, 32-34]. Further, our population was younger and had a lower mean BMI presurgery compared with other studies [14, 22, 23, 26, 32-34].

The mean EWL among those participants that completed the follow-up was more than $80 \%$ and a mean change in BMI of $-12.9 \mathrm{~kg} / \mathrm{m}^{2}$. In a meta-analysis including more than 15,000 patients [35], the mean EWL was $59.5 \%$ in patients having undergone LRYGB. We found that women who were satisfied with their weight loss 1-year post-surgery had a higher \%EWL than women who were not satisfied. Similar results have also been shown by Ziljstra et al. [13]. Nevertheless, all women in our study underwent profound weight loss.

A realistic goal after bariatric surgery, according to Buchwald et al. [1], is an EWL of about $60 \%$. This is similar to the mean $\%$ EWL among women in our cohort who were not satisfied with the result. The pre-surgery expected \%EWL shown in previous studies also illustrates the unrealistic expectations many patients with obesity have upon the result of 
Fig. 1 The three most important reasons to seek bariatric surgery at baseline $(n=50)$ and items of greatest importance for satisfaction 1 year after gastric bypass $(n=40)$ among Swedish women. The participants rated their top three reasons pre- and post-surgery

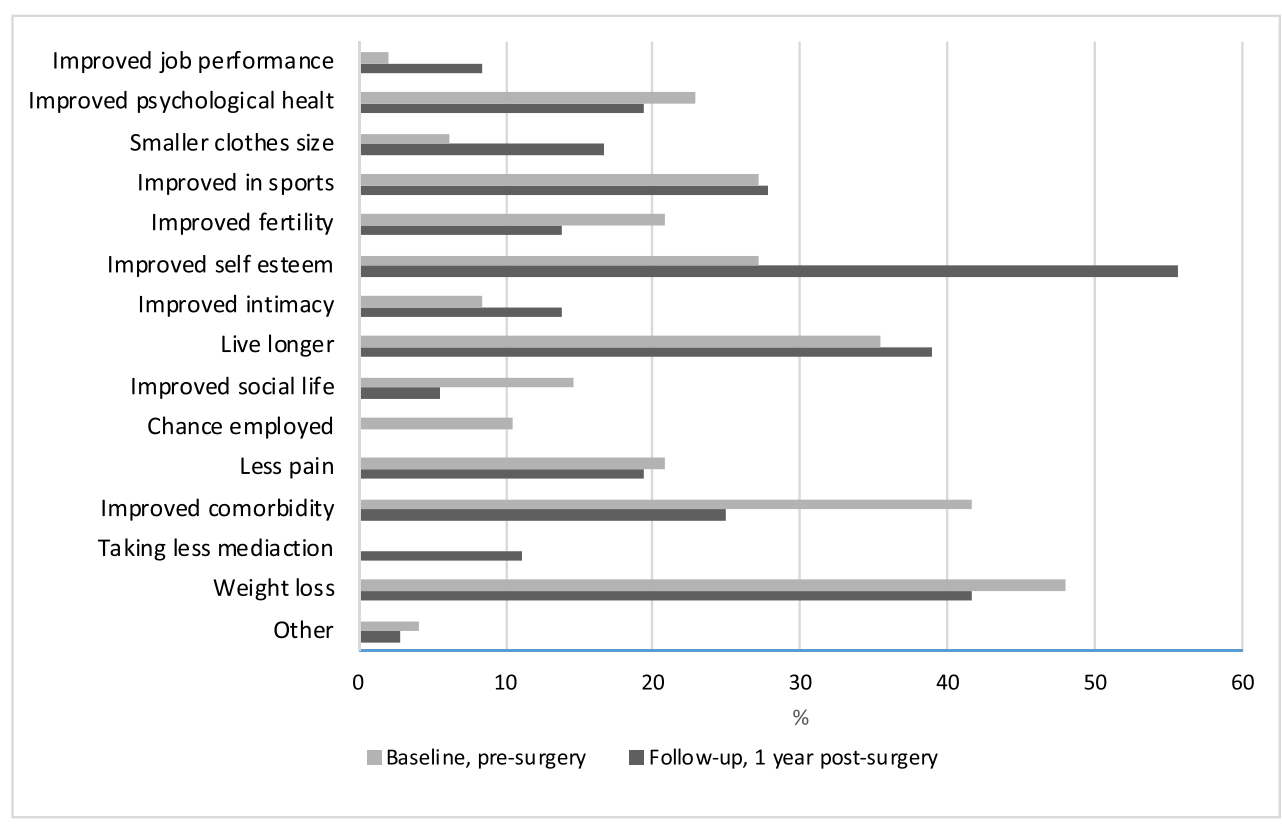

bariatric surgery. For example, the mean \%EWL reported in a study by Wee et al. [4] was $81 \%$, while the "dream" excess weight loss was $94 \%$. In a study by Karmali et al. [17] the level of "acceptable" \%EWL were over 70 while the "happy" level reported by the patients were over 80 . Similar results have also been reported for patients with obesity engaged in non-surgical weight loss treatments [7-9, 36].

Pre-surgery, most participants in our study scored lower mental health than the general Swedish population and this has been shown before [23, 25, 26, 37]. The scores were improved in a majority of our patients 1-year post-surgery, which is in line with several studies from various countries $[23,25,38]$. Improvements in quality of life post-surgery have been shown as early as within 3-month post-surgery in some studies [21, 23]. However, studies with longer follow-up suggest that the improvement may decline over time [24, 25], and some patients might not experience an improvement in mental health at all. For example, we have shown an increased risk of post-surgery self-harm and hospitalization for depression in a nationwide cohort study of patients undergoing gastric bypass [39]. This was however an epidemiological study where we were restricted to use variables available in population-based registries; thereby we were unable to study unrecorded factors such as satisfaction. Decreased mental health may be due to unrealistic expectations and discontent with post-surgery weight result, but little has been known about patient experiences post-surgery.

To our knowledge, this is the first study to assess reason to seek surgery, quality of life and weight loss goals both preand post-surgery, as well as satisfaction with post-surgery weight loss within the same study population. Compliance was high, with a response rate of $80 \%$ at the 1 -year follow-up.
Table 2 Change in body mass index (BMI), percent excess weight loss (\%EWL), and satisfaction in relation to quality of life SF-36 scores among those completing the 1-year post-surgery follow-up. Pairwise difference satisfied-not satisfied tested with the Mann-Whitney $U$ test

\begin{tabular}{lcccc}
\hline & $\begin{array}{l}\text { All }(n=40) \\
\text { Mean (SD) }\end{array}$ & $\begin{array}{l}\text { Satisfied }(n=32) \\
\text { Mean (SD) }\end{array}$ & $\begin{array}{l}\text { Not satisfied }(n=8) \\
\text { Mean (SD) }\end{array}$ & $P$ value \\
\hline $\begin{array}{l}\text { Change in BMI, } \mathrm{kg} / \mathrm{m}^{2 *} \\
\text { \% EWL }\end{array}$ & $-12.9(3.7)$ & $-13.4(3.6)$ & $-11.0(4.1)$ & 0.06 \\
MCS $^{* * * *}$ & $86.9(26.3)$ & $94.6(22.9)$ & $60.0(17.6)$ & 0.002 \\
Pre-surgery & $42.6(12.8)$ & $44.6(13.6)$ & $36.3(12.9)$ & 0.12 \\
Post-surgery & $45.8(14.5)$ & $46.2(13.3)$ & $44.2(19.9)$ & 0.96 \\
$\begin{array}{l}\text { PCS } \\
\text { Pre-surg }\end{array}$ & & & $39.1(11.5)$ & 0.18 \\
Post-surgery & $37.5(12.0)$ & $36.9(12.6)$ & $47.6(13.5)$ & 0.45 \\
\hline
\end{tabular}

* Difference in BMI pre- and post-surgery

*** Percent excess weight loss

*** SF-36, mental component summary scale

**** SF-36, physical component summary scale 
Fig. 2 SF-36, quality of life: the pre-surgery and post-surgery differences of the eight domains, $(n=50)$ respectively $(n=37)$

\section{Short Form-36}

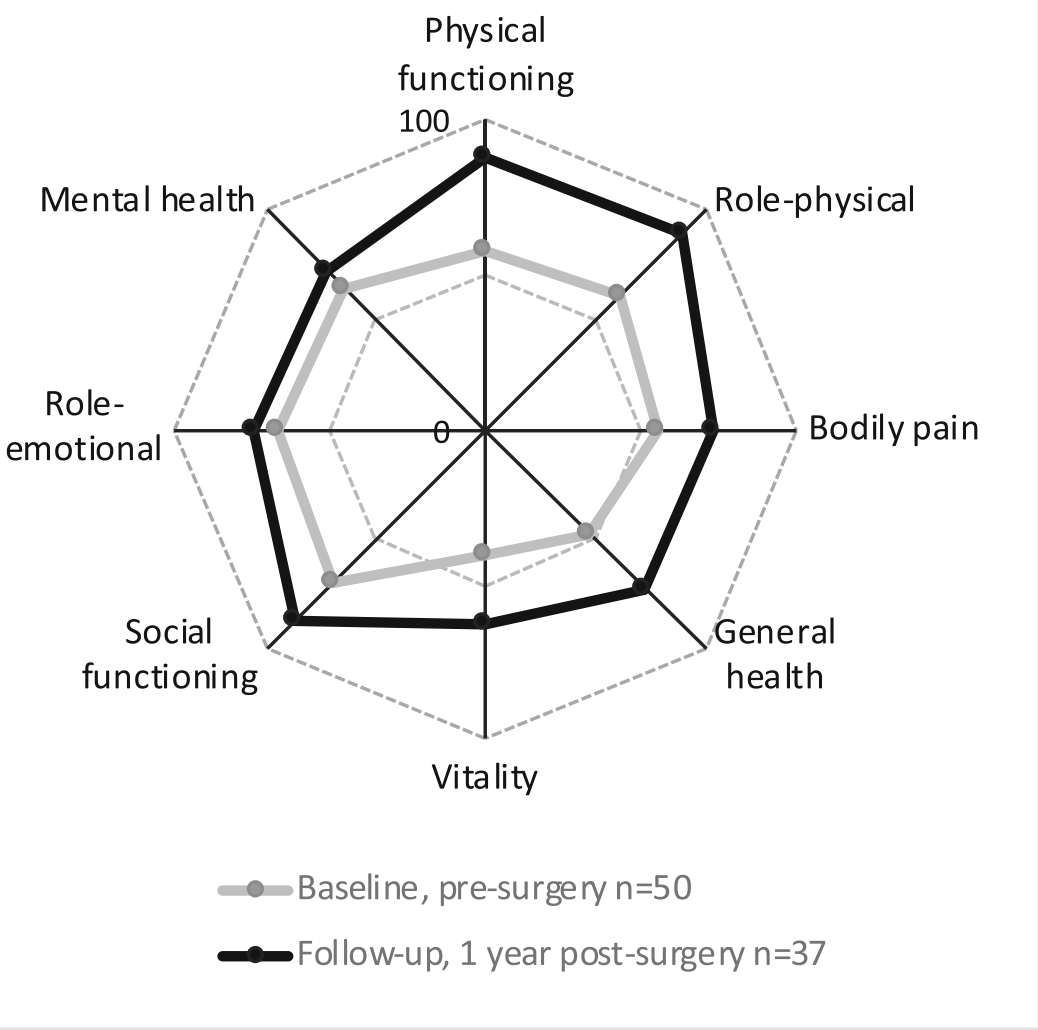

The strengths of this study include the prospective design with a 1-year follow-up and detailed questionnaires with high response rates. We were also able to collect data of weight and health issues from medical records for the few participants who did not complete the study. A potential limitation of our study may be that our population was younger and had less comorbidity than would be expected in the women with obesity undergoing bariatric surgery. This could be due to a selection of healthier subjects without diabetes and related comorbidities choosing to participate. Concurrent with our study, patients with diabetes were asked to participate in another study and might therefore have declined participation in additional studies. Furthermore, this study was only conducted in women thus there may be limited generalizability of our results. Further studies investigating expectations and satisfaction among men undergoing bariatric surgery are warranted.

\section{Conclusions}

Patients' primary reason for seeking surgery was weight loss. Despite profound weight loss, this was not the item of most satisfaction post-surgery, but it was instead improved self-esteem. These results provide valuable insights into the experience of patients following bariatric surgery. Our findings may be useful in the clinical setting when informing patients pre-surgery about what to expect and when meeting patient's post-surgery to discuss results.

Acknowledgments We want to thank the surgeons: Rune Sandbu, Anne Juuti, Signe Röstad, Wouter te Riele, Lars Fischer, Timo Heikkinen and Kai Orava, who together with Mari Hult, developed the questionnaires.

\section{Compliance with Ethical Standards}

Conflict of Interest Mari Hult declares no conflicts of interests or financial disclosures.

Stephanie E. Bonn declares no conflicts of interests or financial disclosures.

Lena Brandt declares no conflicts of interests or financial disclosures.

Mikael Wirén declares no conflicts of interests or financial disclosures.

Ylva Trolle Lagerros declares no conflicts of interests or financial disclosures.

Informed Consent Informed consent was obtained from all individual participants included in the study.

All procedures performed in studies involving human participants were in accordance with the ethical standards of the institutional and/or national research committee and with the 1964 Helsinki declaration and its later amendments or comparable ethical standards. 


\section{Appendix 1}

EOA Questionnaire

Initials: _ _ (Surname . Name)

Age: years

$\begin{array}{ll} & \\ \text { Relationship } & \square \text { single } \\ & \square \text { children } \\ \text { Smoking } & \square \text { yes }\end{array}$

Date and place:

Height: cm Weight: kg BMI: $\mathrm{kg} / \mathrm{m}^{2}$

Occupation

Currently working

$\square$ yes $\square \quad$ no
$\square$ sick leave $\square$ pension $\square$ unemployed

Education $\square$ Education after compulsory school

University

Other

Co-morbidities

\begin{tabular}{|lllll}
$\square$ & Diabetes & medication for diabetes & $\square$ tablets & insulin \\
$\square$ & High blood pressure & medication for hypertension & $\square$ yes & no \\
$\square$ & High cholesterol & medication for cholesterol & $\square$ yes & no \\
$\square$ & Sleep apnea & C-PAP & $\square$ yes & no \\
$\square$ Depression/mood disorder & medication & $\square$ yes & no \\
$\square$ Joint pain & pain killer & $\square$ yes & no \\
$\square$ Infertility & & $\square$ yes & $\square$ no
\end{tabular}

Other weight related disease:

\section{Please, read all questions before you start answering them.}

\section{How much weight do you expect to lose after surgery?}

Mark on the line where you consider yourself to be before surgery with number 1 and where you expect to be after surgery with number 2 on the line.
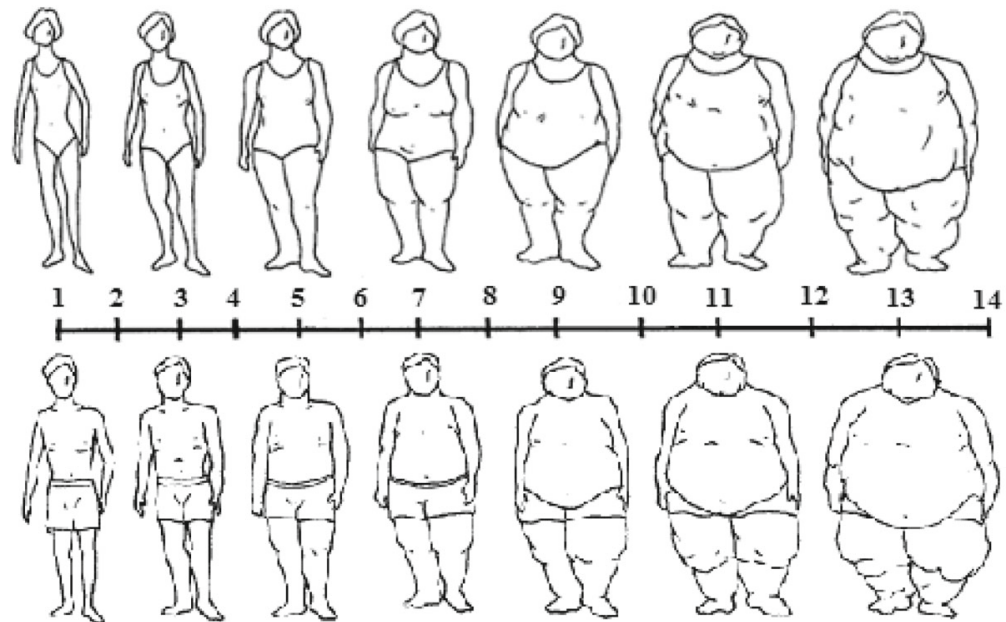

2. How many kilos do you expect to lose by surgery?

kg

3. Please mark on the line the proportion of how much of the weight loss will be due to the operation.

$0 \%$


Each question should be marked with only one answer. Please mark what you think fits your opinion the most. That is, if something is not so important to you please mark this issue with 1 .

Why did you seek for obesity surgery? How important are the following issues, please mark 1 to 5.

not important of some importance

A. Weight loss

B. Taking less medications

C. Improvement of weight related diseases such as diabetes,

High blood pressure, obstructive sleep apnoea etc.

D. Less pain

E. Chance of being employed

F. Chance of better performance at work

G. Improve social life (culture, meeting friends)

H. Live longer

I. To improve intimacy and partnership

J. Improved self esteem

K. Improvement in fertility

L. Improve physical activity and sports

M. Reduction in clothes size

$\mathrm{N}$. Improvement in mood and mental health

O. Other issue that is not mentioned above

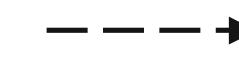

very important

5

$0 \quad 0 \quad 0 \quad 0$

$\bigcirc \quad \bigcirc \quad 0$

$\bigcirc \quad \bigcirc \quad 0 \quad 0$

$\bigcirc \quad \bigcirc \quad 0 \quad 0$

$\bigcirc \quad \bigcirc \quad \bigcirc$

$\bigcirc \quad \bigcirc \quad 0$

$\bigcirc \quad \bigcirc \quad \bigcirc$

$\bigcirc \quad \bigcirc \quad 0 \quad 0$

$\bigcirc \quad \bigcirc \quad \bigcirc$

$\bigcirc \quad 0 \quad 0$

$\bigcirc \quad \bigcirc \quad \bigcirc$

$\bigcirc \quad \bigcirc \quad \bigcirc$

$\bigcirc \quad \bigcirc \quad \bigcirc$

$\bigcirc \quad \bigcirc \quad \bigcirc$

$\bigcirc \quad \bigcirc \quad \bigcirc$

Please rank the three most important of the categories above in order 1 to 3 , with number 1 as most important.

1

2

3 


\section{Appendix 2}

EOA Questionnaire - 1 year follow up

Initials: - _ (Surname . Name)

Age: years

Occupation

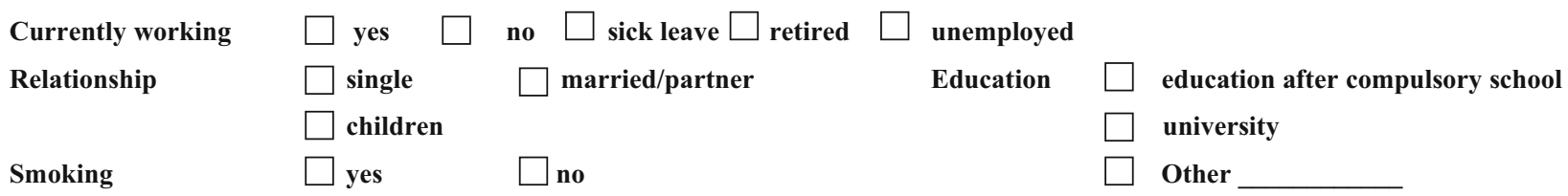

Date and place:

Height: cm Weight: kg BMI: $\mathrm{kg} / \mathrm{m}^{2}$

Co-morbidities

\begin{tabular}{|c|c|c|c|}
\hline Diabetes & medication for diabetes & $\square$ tablets & insulin \\
\hline High blood pressure & medication for hypertension & yes & no \\
\hline High cholesterol & medication for cholesterol & yes & no \\
\hline Sleep apnea & C-PAP & yes & no \\
\hline Depression/mood disorder & medication & yes & no \\
\hline Joint pain & pain killer & $\square$ yes & no \\
\hline
\end{tabular}

Infertility

Other weight related disease:

Please, read all questions before you start answering them.

1. Mark above the line where you were before surgery with number 1 , and with number 2 where you consider yourself now and with number 3 where you would like to be.
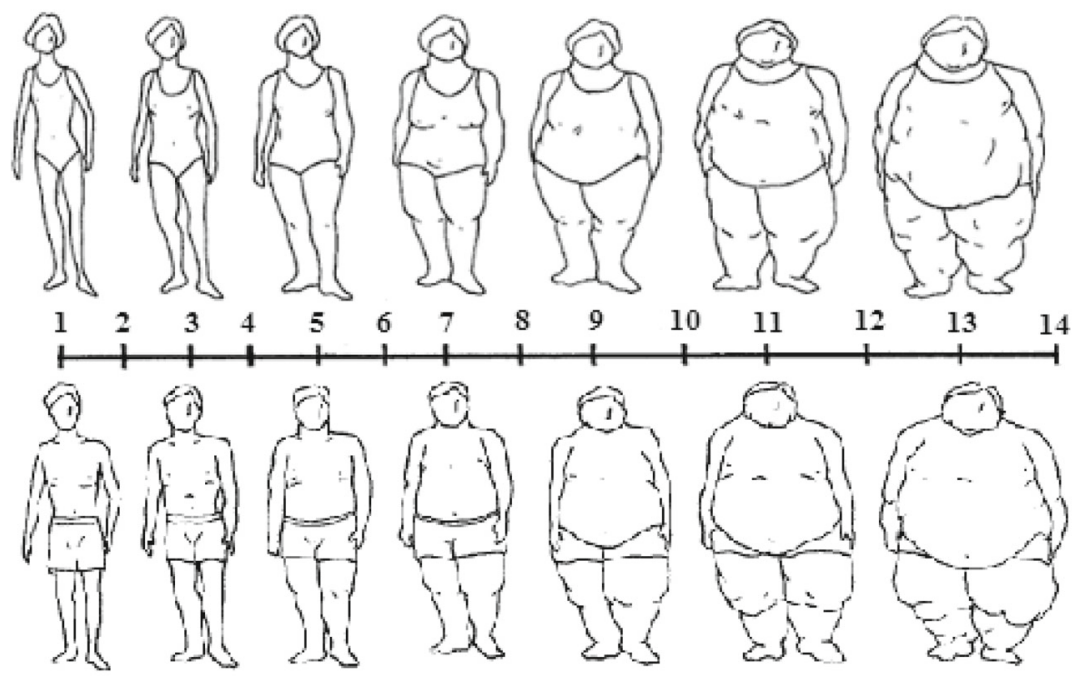
2. How many kilos have you lost after surgery? kg.

Are you satisfied with the weightloss?

yes

no

How many more kilos would you like to loose?

kg

3. Please mark on the line the proportion of how much of the weight loss that has been due to the operation.

$0 \%$

$50 \%$

$100 \%$

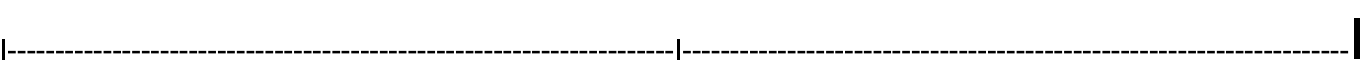


Each question should be marked with only one answer. Please mark what you think fits your opinion the most. Feel free to use the whole range of answers. That is, if something is not so important to you please mark this issue with 1 .

Are you satisfied with the result of bariatric surgery in the following issues? please mark 1 to 5 .

not important $--\longrightarrow$ very important

A. Weight loss

B. Taking less medications

C. Improvement of weight related diseases such as diabetes,

High blood pressure, obstructive sleep apnoea etc.

D. Less pain

E. Chance of being employed

F. Chance of better performance at work

G. Improve social life (culture, meeting friends)

H. Live longer

I. To improve intimacy and partnership

J. Improved self esteem

K. Improvement in fertility

L. Improve physical activity and sports

M. Reduction in clothes size

N. Improvement in mood and mental health

O. Other issue that is not mentioned above

$\begin{array}{lllll}1 & 2 & 3 & 4 & 5\end{array}$

$0 \quad 0 \quad 0$

$\bigcirc$

$\bigcirc \quad$

$0 \quad 0 \quad 0 \quad 0$

$\bigcirc$

$\bigcirc$

$\bigcirc$

$\mathrm{O}$

$\bigcirc \quad 0$

$\bigcirc \quad 0 \quad 0 \quad 0$

$\bigcirc \quad 0 \quad 0 \quad 0$

$\bigcirc \quad 0 \quad 0 \quad 0$

$0 \quad 0 \quad 0 \quad 0 \quad 0$

$0 \quad 0 \quad 0 \quad 0 \quad 0$

$0 \quad 0 \quad 0 \quad 0$

$0 \quad 0 \quad 0 \quad 0 \quad 0$

$\bigcirc \quad \bigcirc \quad 0 \quad 0$

$\begin{array}{lllll}0 & 0 & 0 & 0\end{array}$

Please rank the three most important of the categories above in order 1 to 3 , with number 1 as most important.

1

2

3

Open Access This article is distributed under the terms of the Creative Commons Attribution 4.0 International License (http:// creativecommons.org/licenses/by/4.0/), which permits unrestricted use, distribution, and reproduction in any medium, provided you give appropriate credit to the original author(s) and the source, provide a link to the Creative Commons license, and indicate if changes were made.

\section{References}

1. Buchwald H, Avidor Y, Braunwald E, et al. Bariatric surgery: a systematic review and meta-analysis. JAMA. 2004;292(14):172437. 
2. Birkmeyer NJ, Dimick JB, Share D, et al. Hospital complication rates with bariatric surgery in Michigan. JAMA. 2010;304(4):43542 .

3. Arterburn DE, Olsen MK, Smith VA, et al. Association between bariatric surgery and long-term survival. JAMA. 2015;313(1):6270.

4. Wee CC, Jones DB, Davis RB, et al. Understanding patients' value of weight loss and expectations for bariatric surgery. Obes Surg. 2006;16(4):496-500.

5. Heinberg LJ, Keating K, Simonelli L. Discrepancy between ideal and realistic goal weights in three bariatric procedures: who is likely to be unrealistic? Obes Surg. 2010;20(2):148-53.

6. Homer CV, Tod AM, Thompson AR, et al. Expectations and patients' experiences of obesity prior to bariatric surgery: a qualitative study. BMJ Open. 2016;6(2):e009389.

7. Foster GD, Wadden TA, Phelan S, et al. Obese patients' perceptions of treatment outcomes and the factors that influence them. Arch Intern Med. 2001;161(17):2133-9.

8. Dutton GR, Perri MG, Dancer-Brown M, et al. Weight loss goals of patients in a health maintenance organization. Eat Behav. 2010;11(2):74-8.

9. Crawford R, Glover L. The impact of pre-treatment weight-loss expectations on weight loss, weight regain, and attrition in people who are overweight and obese: a systematic review of the literature. Br J Health Psychol. 2012;17(3):609-30.

10. Calugi S, Marchesini G, El Ghoch M, et al. The influence of weight-loss expectations on weight loss and of weight-loss satisfaction on weight maintenance in severe obesity. J Acad Nutr Diet. 2017;117(1):32-8

11. Peacock JC, Perry L, Morien K. Bariatric patients' reported motivations for surgery and their relationship to weight status and health. Surg Obes Relat Dis. 2018;14(1):39-45.

12. Libeton M, Dixon JB, Laurie C, et al. Patient motivation for bariatric surgery: characteristics and impact on outcomes. Obes Surg. 2004;14(3):392-8.

13. Zijlstra H, Larsen JK, de Ridder DT, et al. Initiation and maintenance of weight loss after laparoscopic adjustable gastric banding. The role of outcome expectation and satisfaction with the psychosocial outcome. Obes Surg. 2009;19(6):725-31.

14. Wolfe BL, Terry ML. Expectations and outcomes with gastric bypass surgery. Obes Surg. 2006;16(12):1622-9.

15. White MA, Masheb RM, Rothschild BS, et al. Do patients' unrealistic weight goals have prognostic significance for bariatric surgery? Obes Surg. 2007;17(1):74-81.

16. Munoz DJ, Lal M, Chen EY, et al. Why patients seek bariatric surgery: a qualitative and quantitative analysis of patient motivation. Obes Surg. 2007;17(11):1487-91.

17. Karmali S, Kadikoy H, Brandt ML, et al. What is my goal? Expected weight loss and comorbidity outcomes among bariatric surgery patients. Obes Surg. 2011;21(5):595-603.

18. da Silva SS, da Costa Maia A. Obesity and treatment meanings in bariatric surgery candidates: a qualitative study. Obes Surg. 2012;22(11):1714-22.

19. Ballantyne GH. Measuring outcomes following bariatric surgery: weight loss parameters, improvement in co-morbid conditions, change in quality of life and patient satisfaction. Obes Surg. 2003;13(6):954-64.

20. Rea JD, Yarbrough DE, Leeth RR, et al. Influence of complications and extent of weight loss on quality of life after laparoscopic Rouxen-Y gastric bypass. Surg Endosc. 2007;21(7):1095-100.

21. Torquati A, Lutfi RE, Richards WO. Predictors of early quality-oflife improvement after laparoscopic gastric bypass surgery. Am J Surg. 2007;193(4):471-5.
22. Busetto L, Mozzi E, Schettino AM, et al. Three years durability of the improvements in health-related quality of life observed after gastric banding. Surg Obes Relat Dis. 2015;11(1):110-7.

23. Julia C, Ciangura C, Capuron L, et al. Quality of life after roux-en$\mathrm{Y}$ gastric bypass and changes in body mass index and obesityrelated comorbidities. Diabetes Metab. 2013;39(2):148-54.

24. Raoof M, Naslund I, Rask E, et al. Health-related quality-of-life (HRQoL) on an average of 12 years after gastric bypass surgery. Obes Surg. 2015;25(7):1119-27.

25. Velcu LM, Adolphine R, Mourelo R, et al. Weight loss, quality of life and employment status after Roux-en-Y gastric bypass: 5-year analysis. Surg Obes Relat Dis. 2005;1(4):413-6. Discussion 7

26. Pilone V, Mozzi E, Schettino AM, et al. Improvement in healthrelated quality of life in first year after laparoscopic adjustable gastric banding. Surg Obes Relat Dis. 2012;8(3):260-8.

27. Sullivan M, Karlsson J, Taft C. SF-36, Svensk manual och tokningsguide, 2:a upplagan, (Swedish manual and interpretation guide 2nd edition) Gothenburg: Sahlgrenska University Hospital 2002.

28. Wee CC, Hamel MB, Apovian CM, et al. Expectations for weight loss and willingness to accept risk among patients seeking weight loss surgery. JAMA Surg. 2013;148(3):264-71.

29. van Hout GC, Verschure SK, van Heck GL. Psychosocial predictors of success following bariatric surgery. Obes Surg. 2005;15(4):55260 .

30. Helmio M, Salminen P, Sintonen $\mathrm{H}$, et al. A 5-year prospective quality of life analysis following laparoscopic adjustable gastric banding for morbid obesity. Obes Surg. 2011;21(10):1585-91.

31. Dymek MP, Le Grange D, Neven K, et al. Quality of life after gastric bypass surgery: a cross-sectional study. Obes Res. 2002;10(11):1135-42.

32. Peluso L, Vanek VW. Efficacy of gastric bypass in the treatment of obesity-related comorbidities. Nutr Clin Pract. 2007;22(1):22-8.

33. Victorzon M, Tolonen P, Sintonen H. Health-related quality of life in severely and morbidly obese patients waiting for bariatric surgery in Finland. Scand J Surg. 2010;99(3):122-6.

34. Jakobsen GS, Hofso D, Roislien J, et al. Morbidly obese patientswho undergoes bariatric surgery? Obes Surg. 2010;20(8):1142-8.

35. Buchwald H, Estok R, Fahrbach K, Banel D, Jensen MD, Pories WJ, et al. Weight and type 2 diabetes after bariatric surgery: systematic review and meta-analysis. Am J Med 2009;122(3):248-56 e5.

36. Foster GD, Wadden TA, Vogt RA, et al. What is a reasonable weight loss? Patients' expectations and evaluations of obesity treatment outcomes. J Consult Clin Psychol. 1997;65(1):79-85.

37. Karlsson J, Taft C, Ryden A, et al. Ten-year trends in health-related quality of life after surgical and conventional treatment for severe obesity: the SOS intervention study. Int J of Obesity (2005). 2007;31(8):1248-61.

38. Lier HO, Biringer E, Hove O, et al. Quality of life among patients undergoing bariatric surgery: associations with mental health- a 1 year follow-up study of bariatric surgery patients. Health Qual Life Outcomes. 2011;9:79.

39. Lagerros YT, Brandt L, Hedberg J, et al. Suicide, self-harm, and depression after gastric bypass surgery: a nationwide cohort study. Ann Surg. 2017;265(2):235-43.

Publisher's Note Springer Nature remains neutral with regard to jurisdictional claims in published maps and institutional affiliations. 